\title{
Modo CAPITALista de SER E NATUREZA: Limites, CONTRADiÇÕES E TRANSCENDÊNCIAS ECOSSISTÊMICAS
}

\author{
Marcelo dos Santos Marques ${ }^{1}$, Eufrasina Campelo Borges Mendonça Barbosa ${ }^{2}$
}

\author{
${ }^{1}$ Doutor em Sociologia, Professor Titular, Instituto Federal do Ceará, Av. Treze de Maio, 2081, Bairro de Fátima, CEP: 60040531, Fortaleza - CE, \\ Brasil. ORCID: 0442-3579-7212-6583 \\ ${ }^{2}$ Mestra em Logística e Pesquisa Operacional, Universidade Federal do Ceará, Campus do Pici, bloco 724, CEP: 60455-760, Fortaleza - CE, Brasil. \\ ORCID: 2405-9881-7975-6421 \\ *Autor para correspondência:eufrasinabarbosa@hotmail.com
}

Recebido em 17 de agosto de 2017. Aceito em 19 de maio de 2018. Publicado em 20 de junho de 2018.

\begin{abstract}
RESUMO - O avanço das forças produtivas, proporcionado pelo desenvolvimento científico-técnico, faz emergir importantes incompatibilidades entre o processo de produção capitalista e a finitude dos recursos naturais do Planeta. O paradigma do crescimento econômico exponencial potencializa problemas sociais e ambientais locais à escala global. Com este artigo, buscamos nos apropriar de uma dialética conceitual para dar conta dos complexos elementos que perfazem o objeto investigado, qual seja, as inter-relações entre economia, sociedade e Natureza. A conclusão geral é que a humanidade caminha a passos largos para uma irreversível crise civilizacional e para a ruptura metabólica estrutural. A depleção da matéria disponível no Planeta compromete a continuidade da civilização inerente ao sistema do capital. Construímos por negação aportes para uma sociedade de transição para além do capital. Frente a proposta hegemônica de crescimento econômico ilimitado, apregoada pela escola econômica neoclássica, ensaiamos um debate que envolve os significados de "desenvolvimento sustentável" e a ideia do "decrescimento econômico" na forma como sugerida pelo economista e filósofo francês Serge Latouche.
\end{abstract}

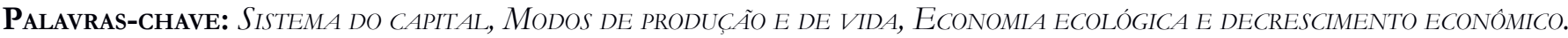

\section{MODO CAPITALISTA DE SER Y NATURALEZA: LÍMITES, CONTRADICIONES Y TRANSCENDENCIAS ECOSISTEMICAS}

Resumen - El avance de las fuerzas productivas, proporcionado por el desarrollo científico-técnico, hace emerger importantes incompatibilidades entre el proceso de producción capitalista y la finitud de los recursos naturales del Planeta. El paradigma del crecimiento económico exponencial potencializa los problemas sociales y ambientales locales a una escala mundial. En este estudio, buscamos apropiarse de una dialéctica conceptual de los complejos elementos que constituyen el objeto investigado, es decir, las interrelaciones entre economía, sociedad y naturaleza. La conclusión general es que la humanidad camina rápido hacia una irreversible crisis de la civilización y para la ruptura metabólica estructural. La depleción de la materia disponible en el Planeta compromete la continuidad de la civilización inherente al sistema del capital. Construimos por negación aportes para una sociedad de transición más allá del capital. Frente a la propuesta hegemónica de crecimiento económico ilimitado, pregonada por la escuela económica neoclásica, ensayamos un debate que involucra los significados de "desarrollo sostenible" y la idea del "decrecimiento económico" como sugiere el economista y filósofo francés Serge Latouche.

Palabras Clave: Sistema del CAPITAL, Modos de PRODUCCIÓN Y DE VIDA, ECONOMÍa ECOLÓGICA Y DECRECIMIENTO ECONÓMICO.

CAPITALIST MODE OF BEING AND NATURE: ECOSYSTEM LIMITS, CONTRADICTIONS AND TRANSCENDENCIES

ABstract - The advance of the productive forces, brought by scientific and technical development, brings important 
incompatibilities between the capitalist production process and the finitude of the Planet's natural resources. The paradigm of exponential economic growth potentiates local social and environmental problems on a global scale. With this paper, we seek to appropriate a conceptual dialectic for the complex elements that make up the investigated object, that is, the interrelations between economy, society and Nature. The general conclusion is that humanity is striding towards an irreversible civilizational crisis and structural metabolic rupture. The depletion of available matter on the Planet compromises the continuity of capital civilization. By negation, we construct contributions towards a transitional society beyond capital. Faced with the hegemonic proposal of unlimited economic growth, thought by the neoclassical economic school, we rehearsed a debate that involves the meanings of "sustainable development" and the idea of "economic degrowth" as suggested by the French economist and philosopher Serge Latouche.

KEYWords: CAPITAL SYSTEM, MODES OF PRODUCTION AND LIFE, ECOLOGICAL ECONOMICS AND DEGROWTH ECONOMICS.

\section{Para início de CONVERSA}

Para dialogarmos sobre a relação contraditória entre o sistema de produção do capital, seu inerente modo de vida e a Natureza, é preciso demarcar preliminarmente o significado geral do que se entende por "sistema". Para iniciarmos nosso diálogo, é necessário afirmar que todo organismo vivo, seja ele um vírus, uma bactéria ou uma molécula, compreende um sistema. Um bioma conforma um organismo associativo ecossistêmico complexo permeado de singularidades. Assim, todas as plantas e animais isoladamente ou em conjunto constituem sistemas. Cada ser tomado isoladamente também perfaz uma totalidade orgânica. Suas partes componentes compreendem relações, padrões e conexões. Seus membros constitutivos são ao mesmo tempo autorreferenciados e correlacionados. Eles se constituem em redes auto-organizadoras, cujos componentes estão todos interligados e são interdependentes (Capra et al. 2006).

Conforme Meadows (2008), um sistema compreende um conjunto de elementos, que podem ser pessoas, células, moléculas, estruturas, instituições ou outros elementos, interconectados de tal modo que produzem, ao longo do tempo, o padrão de comportamento que lhe é adequado. Como uma totalidade integrada, todo e qualquer sistema perpassa três condicionantes: seus componentes, suas interconexões e suas funções e/ou finalidades. Cada um a seu modo, a Natureza e o modo de produção de mercadorias, compreendem sistemas metabólicos complexos, que operam de maneira independente e apresentam dispares composições, relações e funcionalidades. Em um ecossistema essa relação é natural, em um sociometabolismo como a sociedade capitalista há uma relação de domínio exterior derivada de uma dominação abstrata e imperiosa edificada sobre a relação capital-trabalho.

Tanto em um caso como noutro, essa integração não é sinonímia de ausência de conflitos e de transmutações sistêmicas. Na Natureza, há estabilidade, permanências e mutações, mas como a vida apresenta propriedades auto-organizadoras e autotranscendentes também há desenvolvimento e evolução progressiva. Existe, portanto, um equilíbrio prevalecente sujeito a existência de desequilíbrios e esgotamentos entrópicos. A sociedade (baseada na produção do valor), edificada sobre contradições que lhe são imanentes (relações de classes e de interesses), que acompanham toda sua vida metabólica, encontra seu antagonismo sistêmico fundamental (limite absoluto interno) na substituição do trabalho morto por trabalho objetivado (Marx 1972, vol. 2). Esse sociometabolismo se depara com seu esgotamento (limite absoluto externo) na impossibilidade de explorar, ad infinitum, os recursos ambientais na intensidade que tem extraído matéria-prima e matéria-bruta e produzido energia.

O organismo humano é um tipo de sistema biológico conformado por outros tantos sistemas. Seus órgãos 
se interligam por um sofisticado processo de reações físico-químicas, cuja função (finalidade) é a de extrair dos alimentos ingeridos os nutrientes essenciais e distribui-los por todo o corpo por intermédio da circulação sanguínea retroalimentado pelo coração. Tanto a circulação sanguínea quanto o coração compreendem, per si, sistemas. O funcionamento de cada órgão depende da performance dos demais. A distribuição dos nutrientes segue uma "logística" complexa de armazenamento e transporte que resultaram da transformação metabólica de matéria e energia em elementos nutricionais. O corpo humano como totalidade é assim mantido, e a espécie reproduzida. O produto final, contudo, é a descarga de resíduos não reutilizáveis. Esse é o padrão seguido por todos os organismos vivos que se reproduzem na Terra.

Pensar em termos de padrões requer que percebamos certas relações dinâmicas que se estabelecem na Natureza, as quais se repetem e lhes confere certa estabilidade. A vida biológica é autógena isso justifica as células se autorregenerarem continuamente, por exemplo. Como a vida é auto-organização, cujos fluxos regulares requerem estabilidade e mudanças contínuas, refleti-la exige raciocinarmos de modo processual. Reflexionar em termos ambientais nos obriga que desenvolvamos um entendimento a partir de conexões, ponderando a interdependência e as relações de contexto que existem, por exemplo, entre os fatores bióticos e abióticos, como os aspectos físico-químicos que integram determinado meio ambiente. Em uma cadeia alimentar há relações de equilíbrio ao mesmo tempo cooperativo e conflitivo. É preciso desenvolver a competência sistêmica a qual nos remete a uma mudança epistemológica de um reducionismo baseado em causalidades e efeitos mecânicos e imediatos para um complexo conjunto das relações e padrões que se imbricam na totalidade do real.

Como o objeto de estudo analisado neste artigo intitulado Modo capitalista de ser e Natureza: limites, contradições e transcendências ecossistêmicas, localiza-se nas inter-relações entre economia, sociedade e Natureza, buscaremos nos apropriar de uma dialética conceitual para dar conta dos complexos elementos que perfazem o objeto investigado: o modo de produção do capital, com seu tautológico mecanismo autorreferenciado de produção do valor; a sociedade capitalista com seus correspondentes estilos de vida e de consumo e; as relações sociometabólicas que estabelecemos com a Natureza nos processos de produção e reprodução da vida material. Procuraremos demonstrar que a humanidade caminha a passos largos para uma irreversível crise civilizacional e para a ruptura metabólica estrutural. Intentaremos construir por negação aportes para uma sociedade de transição para além do capital. Para tal, essas esferas (Economia, Sociedade e Natureza) serão tratadas como sistemas particulares, mas não autônomos, de modo a apreendermos suas interconexões e, sobretudo, a hierarquia que entre eles se estabelece.

A sociedade e a economia são sistemas imbricados. Juntos envolvem pessoas, estruturas, instituições, atividades produtivas, normas etc. Ambos se organizam e funcionam tendo a biosfera como invólucro protetor. O ecossistema planetário, por sua vez, corresponde a uma diversidade de interconexões ecossistêmicas que se distribuem pela superfície e profundezas do Planeta. Como os seres humanos não possuem sua subsistência imediatamente dada, eles precisam estabelecer mediações com a Natureza de modo a transformá-la, caracterizando sua dependência do espaço em que estão inseridos. A biosfera compreende um sistema autógeno e autossuficiente, porém seus recursos transformáveis pela ação humana são limitados. Se a ilimitada e irrefreável produção mercantil não levar em conta a condição circular do Planeta e a capacidade de resiliência da Natureza poderemos leva-la ao esgotamento. Em decorrência, essa contradição pode conduzir ao eclipse do sistema baseado na produção de mercadorias.

Na primeira parte do artigo buscamos demonstrar como opera o sistema do capital e como o modo de vida 
contemporâneo se moldou às suas necessidades expansivas. Partimos do pressuposto de que a relação social baseada no dinheiro, inerente à produção mercantil, coere os trabalhadores ao alienar sua força de trabalho para produzir mercadorias e receber em troca uma parcela do valor por eles mesmos criado. No final, trabalhadores e capitalistas aparecem na esfera da circulação como "usufrutuários" mútuos para estampar a democracia neoliberal da livre escolha. Embora tendo capacidade aquisitiva e objetivos distintos, trabalhadores e capitalistas estão sujeitos ao poder social geral do dinheiro. Os primeiros são obrigados a vender sua força de trabalho para em troca obterem os bens necessários que lhes permitem acesso ao frenesi do mundo das mercadorias; os últimos investem dinheiro para abiscoitarem mais dinheiro. Por outro lado, os capitalistas, estimulados pelas "forças de mercado" a adquirir máquinas e equipamentos mais aperfeiçoados, buscam expandir sua respectiva capacidade produtiva e o poder de competitividade, terminam pondo em ação a contradição central do sistema do capital ao substituírem os trabalhadores diretos por máquinas. De sua parte, a Natureza, subsumida a relação mercantil, termina sendo degradada a condição de mero fator de produção do capital.

Na segunda subunidade realizamos um resgate sobre a forma como se constituíram as relações dos homens entre si e deste com a Natureza nas designadas comunidades primitivas. Elas se deram em respeito ao limite adverso das condições materiais de vida encontradas na Natureza. Em meio à rudeza das condições naturais prevalecentes e em respeito às forças da Natureza, foram brotando os condicionantes de seus modos de vida individuais e coletivos. Essa reconstrução nos serve de contraponto às relações socioambientais alienadas e reificadas desencadeadas a partir do advento da sociedade produtora de mercadorias. Relações estas que foram levadas ao limite a partir do aprofundamento da crise de valorização do capital, quando seu sistema se depara com seus limites estruturais, interno e externo, que poderão conduzi-lo ao esgotamento: trabalho e Natureza.

$\mathrm{Na}$ terceira e última seção, frente à proposta hegemônica de crescimento econômico ilimitado, apregoada pela escola econômica neoclássica, ensaiamos um debate que envolve os significados de "desenvolvimento sustentável" e a ideia do "decrescimento econômico" na forma como sugerida pelo economista e filósofo francês Serge Latouche, em Pequeno tratado do decrescimento sereno. Nesse momento, refletimos a impossibilidade da existência de um planejamento sustentável e sistemático no contexto da sociedade capitalista. A constituição de um "sistema mundo" (Wallerstein 1979) e colonização de todos os setores da vida pelo capital contrapomos a formação de uma organização social forjada a partir do plano do território local, estruturada em escala comunal. Assinalamos, ainda, que os processos econômicos terão que ser orientados por leis que regem a dinâmica dos ecossistemas. Isto nos remete a uma nova consideração do tempo ecossistêmico, contrária àquela inerente ao sistema do capital, mas condizente à regeneração do meio ambiente.

\section{O DINHEIRO, A PRODUÇÃo DO VALOR E SEU CORRESPONDENTE MODO DE VIDA}

A economia capitalista pode ser interpretada como um organismo ou sistema sociometabólico, uma vez que transforma matéria e energia em mercadorias e resíduos e dejetos, interconectando, por funções bem definidas, meios de produção, força de trabalho e correlatas estruturas políticas e sociais, cujo "padrão" (finalidade) é a produção do valor a partir da apropriação de um sobre tempo de trabalhado realizado e não pago. Esse metabolismo é encoberto por uma névoa que impossibilita que se percebam sua natureza sistêmica. Marx, em $O$ Capital, afirma que a sociedade capitalista se apresenta a partir de um átomo essencial, a mercadoria: "A riqueza das sociedades em que domina o modo de produção capitalista aparece como uma 'imensa coleção de mercadorias', 
e a mercadoria individual como sua forma elementar" (1985, p. 45). É como se em decorrência dessa célula básica, vivêssemos em meio a um imenso tecido composto de organismos multicelulares interdependentes (mercadorias) intercambiados entre si pelas vias da mediação do dinheiro.

Por traz de uma aparente relação equitativa de trocas mercantis e de uma ilusória permuta de equivalentes se esconde a forma moderna de como o dinheiro se transforma em mais dinheiro a partir da mediação da produção de mercadorias. Em verdade, a troca de valores de dispares qualidades e distintas proporções e grandezas só é possível a partir do estabelecimento de um elemento comum contido em todas as mercadorias a despeito de suas dimensões qualitativas. Esse componente é o tempo de trabalho dispensado na produção das mercadorias. Isto é, o quantum de tempo de trabalho (trabalho abstrato) desprendido e incorporado em cada unidade mercantil produzida no processo de transformação imediata de uma mercadoria inicial (matéria-prima, matéria-bruta e energia) em uma mercadoria final.

Os avanços científico-tecnológicos, ao acelerarem o tempo de produção, possibilitam a fabricação de uma maior quantidade de mercadorias no mesmo tempo de trabalho, o que conflui para explicitar a contradição central do sistema do capital. Como esses incrementos se dão a medida das necessidades de reprodução ampliada capitalista, paulatinamente os trabalhadores imediatos vêm sendo substituídos por máquinas automáticas, desencadeando, nos termos utilizados por Marx nos Grundrisse, o movimento de sua "contradicción en proceso" (1972, vol. 2, p. 229). Como resultado desse antagonismo sistêmico, a alíquota parte de valor contido em cada mercadoria individual vem diminuindo, na mesma proporção em que decorre a substituição do trabalho humano imediato (trabalho-vivo) por maquinismos autorreferenciados (trabalho-morto / trabalho pretérito). Com efeito, se esvai a substância do valor (tempo) contido em cada unidade mercantil, determinando que se restrinja a própria base valorização do capital. De sua parte, os trabalhadores imediatos são reduzidos à categoria de apêndice de maquinismos automáticos autorreferenciados, restando-lhes ações complementares e atividades de suportes aos complexos automáticos:

La actividad del obrero, reducida a una mera abstracción de la actividad, está determinada y regulada en todos los aspectos por el movimiento de la maquinaria, y no a la inversa. La ciencia, que obliga a los miembros inanimados de la máquina - merced a su construcción - a operar como un autómata, conforme a un fin, no existe en la conciencia del obrero [...] (Marx 1972, vol. 2, p. 219).

Como consequência imediata do dilatamento da contradição central demandada pela crescente subsunção do trabalho, da ciência e da tecnologia à produção mercantil, ocorre o designado desemprego estrutural. Um desemprego que se desenvolveu a partir de uma crescente oferta de força de trabalho frente uma demanda reprimida, que transcende aos momentos conjunturais recessivos, provindos de crises de superprodução e subconsumo. Uma disponibilidade que ultrapassa o clássico "exército industrial de reserva" gerando uma "força de trabalho crescentemente supérflua" (Mészáros 2002, p. 341), já não mais integrável ao processo sistêmico de valorização do capital. Um desemprego inerente ao atual modo de operar do sistema do capital, baseado na crescente ampliação de sua composição orgânica. Como resultado, forma-se uma população extranumerária, "refugo em potencial" (Bauman 2005b, p. 115), cujo destino social é o de se transformarem em resíduos humanos. Uma população extranumerária e sobrante que fica ao largo do mercado de trabalho e da esfera de consumo.

As constantes transformações nas forças produtivas associadas ao espectro do desemprego põem em pânico os trabalhadores quanto às incertezas presentes e o futuro do "mundo do trabalho". Muitos já não mais 
conseguem se vender como força de trabalho. O manter-se empregado exige uma crescente qualificação, requer uma constante apropriação de saberes e fazeres que tendam a serem rapidamente consumidos e descartados na forma de uma "qualificação-desqualificante" (Oliveira 2006 e Marques 2016). Nesse contexto, não há garantias que possibilitem aos trabalhadores uma existência presente coerente com a promessa de vida futura. Esse cenário de incertezas provoca inseguranças psicossociais, gerando patologias como estresse, angustia e depressão, doenças como a Sindrome de Burnout'. Por outro lado, a conjunção desses fatores deletérios vem contribuindo para que se fragilizem as organizações dos trabalhadores e para que se degradem suas condições de vida.

A idílica sociabilidade das trocas perfeitas entre capital e trabalho como predita pela ideologia do credo econômico neoclássico, tende a se desmoronar. Seu ímpeto de crescimento é imanente à lógica que orienta o crescimento econômico a qualquer custo. Para se autovalorizar, ele subsumiu a si o trabalho, a ciência, a tecnologia e a Natureza, dissolvendo-os a condição de meros fatores de produção. "Afirma-se, assim, como o mais colossal extrator de excedente até então conhecido pela humanidade" (Oliveira 2006, p. 24). Como consequência, ele tornou-se um sistema mundo, colonizando todos os setores da vida. Não obstante, o processo de alargamento de suas possibilidades sistêmicas o conduzirá ao seu limite absoluto interno: a impossibilidade de se valorizar.

Como um sociometabolismo "incontrolavelmente voltado para a expansão" (Mészáros 2002, p. 131), cedo ou tarde sua produção econômica encontrará seus antagonismos externos nos estoques de matéria e de energia disponíveis na Terra. Assim, nas relações entre o processo econômico capitalista e os limites energéticos e materiais planetários situa-se o cerne do conflito civilizacional da era Moderna. Desse modo, “[...] a relação com a natureza se constitui um limite para a acumulação do capital, que não pode ser superado ou contornado independentemente das soluções tecnológicas, sociais e culturais que se possam apresentar" (Harvey 2011, p. 153). Como visto anteriormente, essa contradição expressa a incompatibilidade que decorre da acumulação ilimitada do capital e a finitude do Planeta, o que projeta sérias restrições à reprodução da espécie humana. Mais ainda, em virtude de sua finalidade tautológica, qual seja, a produção pela produção, mais precisamente, o acúmulo de dinheiro para gerar mais dinheiro, a racionalidade deste sistema afigura-se como a mais irracional forma de sociabilidade já existente.

De sua parte, o dinheiro é um nexo material alienado que se pretende autônomo frente àqueles que executam as funções necessárias à reprodução do capital. Esse poder que se localiza na estreiteza de suas relações sociais de produção toma para si a condição de “nexo social” (Marx 1972, vol. 1, p. 84). Nessa pré-condição ele organiza a sociedade, constitui e hierarquiza as classes sociais, impõe jogos de interesses a agentes sociais individuais e coletivos, estabelece relações sociais e de trabalho, assenhora e objetifica, pelas vias de sua posse apropria-se de modo privado de bens sociais, assemelha e desassemelha, nivela e descrimina, inclui e exclui do mercado, apaga e impõe diferenças etc. Em verdade, o dinheiro foi guindado à condição de deus da modernidade, ele se assenhorou das pessoas impondo-lhes reações reificadas. Em busca de uma resposta sobre os motivos pelos quais nos sujeitamos a essa coisificação, Sennett nos interroga: "Afinal, o que levou o público a acreditar que bens materiais tão uniformes poderiam ter associações psicológicas? Por que acreditar numa coisa como se ela fosse humana?” (1998, p. 36).

Pela via do consumo, o dinheiro se introjeta nas pessoas de maneira insidiosa por meio do qual absorve suas subjetividades, se interiorizando em seus egos e superegos, permanentemente estimulados pelas diversas mídias

1 Doença que vincula o estado estresse crônico ao exercício cotidiano do trabalho, que conduz o trabalhador a exaustão, a falta de energia e ao esgotamento físico e mental. 
que se desenvolvem nos espaços de apropriação da mais-valia socialmente produzida. Os meios de comunicação são alimentados pelo excedente gerado no âmbito da produção de mercadorias. A fração que lhes cabe nas contas publicitárias das empresas que compõem a totalidade dos capitais é investida na produção (imaterial) de mercadorias, cuja função é estimular incessantemente o fluxo de dinheiro proveniente das compras e vendas de outras mercadorias, e assim sucessivamente. Daí porque a sociedade capitalista pode ser dita a sociedade das mercadorias e a mídia (o espetáculo) pôde se transformar em sua síntese que expressa a reificação das relações sociais em nossa contemporaneidade: “O espetáculo em geral, como inversão concreta da vida, é o movimento autônomo do não vivo" (Debord 2013).

O sistema do capital é, portanto, uma totalidade complexa em que estruturas e suas respectivas funções se interconectam para cumprir a finalidade de sua reprodução em escala ampliada: a valorização do valor. Todos os elementos que o compõem, o consolidam como uma forma de dominação em favor de seu ímpeto progressivo de reprodução. Quando o Estado atua em prol das questões sociais, a economia "sofre" e seus porta-vozes pressionam para que a trajetória do crescimento seja retomada, recorrendo a quaisquer instrumentos disponíveis nas estruturas jurídicas e políticas. As conquistas sociais por ventura alcançadas deverão ser imoladas para que o sistema seja postergado. Os limites de resiliência "do sistema ecológico que é o suporte físico vital de todo sistema produtivo" (Leff 2015, p. 84) serão ultrapassados para possibilitar a expansiva e ilimitada produção de mercadorias.

A ação substitutiva de trabalho imediato por máquinas automáticas é a contradição central porque aciona limites à reprodução do sistema, anunciando a impossibilidade de se substituir infinitamente o trabalho vivo por trabalho morto. Como resultado dessa ação supressiva ocorre à perda de importância da dimensão subjetiva no processo de produção de mercadorias provocando, simultaneamente, consequências sociais e pessoais profundas. Ela reduz o produtor direto à condição de mero vigilante e regulador do movimento das máquinas, esvaziando seu sentimento de pertença e de identificação com a atividade imediata, o que contribui para afirmar sua completa indiferença física e espiritual no fazer cotidiano. A venda de sua força de trabalho afirma-se definitivamente apenas um meio de subsistência para "ganhar a vida". Concretamente, um artifício para obter dinheiro e precariamente se integrar ao processo de consumo mercantil. Afinal, "na sociedade dos consumidores, ninguém pode se tornar sujeito sem primeiro virar mercadoria” (Bauman 2005a, p. 20).

$\mathrm{Na}$ produção, os capitalistas têm que agir consoante às demandas produtivas emanadas do movimento da contradição central buscando a valorização do valor incansavelmente e os trabalhadores têm que compulsoriamente vender sua força de trabalho. Na esfera da circulação, o capital para se realizar faz com que suas necessidades de consumo mercantil apareçam para seus compradores como um algo que subjetivamente almejam para si. Assim, ele estrutura as ações sociais dos seres humanos, independentemente do saber e da vontade destes mesmos indivíduos, reduzindo-os a suas personas. É ele quem demarca nossos modos comportamentais e estilos de vidas. Por isso, o sistema do capital deve ser interpretado para além de um metabolismo material, uma vez que não só produz mercadorias físicas-materiais, mas também gera aspirações psicofísicas, modos comportamentais e desejos de consumo. Suas ações objetivas terminam demandando nossas subjetividades e impactando nossas relações intersubjetivas, se refletindo nas formas como nos comportamos no plano sociocultural e como nos relacionamos com a Natureza. Afinal, "a lógica que leva a dominar classes, oprimir povos e discriminar pessoas é a mesma que leva a explorar a natureza" (Boff 2009, p. 39).

Para fazer frente à crise econômica de 1929 e mais recentemente para dar vazão à crise de valorização do 
capital, a ciência capitalista investiu na redução do tempo de vida útil das mercadorias. O descarte laboratorialmente planejado dava início a um novo ciclo produtivo. Os consumidores passaram a serem conduzidos a consumir consoante os padrões ditados pela mídia e a descartar na forma de lixo produtos ainda úteis, nascia assim à obsolescência perceptiva. A redução da vida útil das mercadorias, associada ao consumismo, expressa o modo de vida prevalecente na sociedade capitalista em nossa contemporaneidade. Juntas, revelam que o destino final dos processos econômicos é o descarte e a crescente produção de resíduos e rejeitos. Como um efeito colateral, mas imanente a dinâmica do sistema produtor de mercadorias, sua produção termina sendo descartada na forma de lixo. Como suas necessidades produtivas são lineares e crescentemente expansivas, a extração e o consumo de matéria e de energia e a emissão de detritos também se dão na mesma proporção ampliada. A economia capitalista e o consumismo formam, assim, um "par perfeito": juntos, o modo de produção do capital e o modo de vida da sociedade capitalista exercem fortes pressões sobre o ambiente.

Claro está, que o sistema do capital não só produz mercadorias físicas-materiais, mas também gera desejos psicossociais, modos comportamentais, latências de consumo. Ele demarca nossas relações intersubjetivas, impactando sobre a forma como nos comportamos no plano sociocultural, estimulando desejos consumistas. Faz com que suas necessidades de consumo de mercadorias apareçam para seus compradores como um algo que subjetivamente almejam para si. Como estas necessidades são inesgotáveis, o consumidor tipo-ideal é aquele que vive intensamente uma relação não realizada de insatisfação pelo consumo. Essa incompletude se explica pelo fato de que “o consumismo não se refere à satisfação de desejos, mas à incitação do desejo por outros desejos sempre renovados - de preferência do tipo que não se pode em princípio saciar” (Bauman 2009, p. 120).

Em verdade, é o capital quem demanda nossos modos comportamentais e estilos de vidas. A necessidade de abrir novo ciclo produtivo o obriga a ativar aos setores de engenharia mercantil para planejarem a obsolescência das mercadorias e a investirem em marketing para constantemente gerar novas demandas consumistas. Em resposta, nossas subjetividades se dissolvem em um eterno processo de reformulação mercantil: "a alteração do padrão de consumo exige que os consumidores remodelem a si mesmos como mercadorias" (Bauman 2005a, p. 13). Tornamo-nos mônadas, não-pessoas que se expressam por meio de um frenético tomar para a si mesmo o ideal de ser mercadoria.

\section{Sociedade E NATUREZA: SABERES TRAdicionais FrENTE À ALIENAÇÃo CAPITALISTA}

Sem pretendermos fazer um resgate histórico de todas as condições concretas vividas por cada sociedade em cada época e lugar, apresentamos uma ilustração sobre as relações de produção e as trocas metabólicas de primeira ordem estabelecidas entre os seres humanos e a Natureza que se processaram nas antigas sociedades comunais, antes do advento da propriedade privada e da sociedade de classes. Fixaremos nosso resgate nas condições materiais em respeito às ideias apresentadas por Marx e Engels na $A$ ideologia alemã quando afirmam que: "O modo como os homens produzem seus meios de vida depende, em primeiro lugar, da natureza dos próprios meios de vida encontrados e reproduzir” (Marx e Engels 1984, p. 15). Essa breve recuperação histórica se justifica pela delimitação do espaço desse escrito e pela necessidade de efetuarmos um contraponto as relações sociais de produção e as mediações de segunda ordem produzidas com a Natureza, decorrentes do advento da 
sociedade capitalista.

Nas comunidades primitivas os homens integravam-se ao ambiente, principalmente, com o objetivo de satisfazer suas necessidades vitais. Nos primórdios, organizados em pequenas hordas e bandos nômades, deslocavam-se constantemente em busca de alimentos. Orientados pelos ciclos da Natureza, imitavam, de certa maneira, o comportamento dos outros animais. Sua capacidade de adaptação foi um fator decisivo para a sua sobrevivência. Eles observavam a Natureza na condição de caçadores e coletores. Para se alimentarem, colhiam frutos, nozes, folhas e raízes das árvores, caçavam pequenos animais e pescavam; para se abrigarem do frio faziam uso das peles de suas caças como vestimentas; para se protegerem dos grandes animais viviam parcialmente sobre árvores e/ou moravam em cavernas. As ferramentas de trabalho paleolíticas eram rudimentares, formadas por lascas de pedra, pedaços de ossos e paus. Para Engels (2009), grande legado desse período é o desenvolvimento da linguagem articulada.

Os primeiros contatos dos homens primitivos com o fogo ocorreram no decurso de suas vidas cotidianas em contato com a Natureza: árvores atingidas por raios e queimadas provocadas pelos raios solares, larvas vulcânicas etc. Aos poucos foi se apercebendo das propriedades imanentes do fogo como o calor e luz. A descoberta de seu fabrico, obtido por fricção, lhes possibilitou o abandono da vida nômade, a fixação no solo e uso de tubérculos farináceos cozidos em buracos feitos ao chão. A escolha do lugar para se estabelecerem se dava em respeito às condições naturais encontradas: a abundância de água e a escolha de ambientes que apresentassem mais possibilidades de caça, pesca e de coleta de frutos. A construção de residências fixas alterou as relações sociais. Enquanto uma caverna abrigava muitas vezes a todos àqueles que compunham uma horda, a construção de casas lhes possibilitou a separação em grupos menores, fazendo surgir os núcleos familiares. A invenção do arco e da flecha tornou a alimentação uma atividade regular. A produção de instrumentos como vasos realizados a base de pedra polida lhes autorizou a estocar alimentos.

Nessa época, com um prolongamento das atividades familiares, o trabalho começou a ser dividido conforme o gênero e a idade e em respeito à condição física: os homens se dedicavam às atividades que exigiam o dispêndio de uma maior força física como a caça e a pesca e as mulheres cuidavam da coleta dos frutos silvestres e das demais atividades domesticas; as crianças acompanhavam aos pais imitando-os em suas atividades cotidianas; cabia aos idosos o exercício de atividades mais leves como o acompanhamento das crianças e o de preservar e transmitir a cultura prevalecente. Essa condição associativista lhes permitiu fazer frente às vicissitudes provenientes de uma natureza que thes era hostil. Nesse processo de adaptação, escolhiam-se lugares com disponibilidade de alimentos, condições de segurança e de clima ameno; não havia motivos para abandonar as terras onde estavam vivendo. Com o fim da vida nômade, começava o desenvolvimento de pequenas vilas.

Ao perceberem que podiam "controlar" a Natureza, isto é, preverem seus fenômenos e se protegerem do rigor das estações do ano, criaram as condições objetivas para se fixar em determinados lugares. Demorar mais tempo em uma região lhes possibilitou, por exemplo, perceberem o comportamento hortícola verificando que uma semente poderia dar origem a uma nova planta. Esse exercício de observação (pesquisa) os credenciou a cultivarem algumas espécies vegetais, consoante diversidade da flora de cada região. Do mesmo modo, analisando a Natureza e o comportamento de algumas espécies de animais aprenderam a domesticá-los. A alimentação deixava de depender da coleta na forma da natureza bruta. Ao se fixarem, criaram condições para tornar seus instrumentos e ferramentas mais adequados à atividade agrícola, à caça e pesca, além do fabrico de petrechos que lhes serviam para defesa contra invasores. A descoberta dos metais lhes possibilitou o fabrico 
de instrumentos de trabalho mais resistentes, potentes e duráveis. O uso de arados metálicos lhes comportou o desenvolvimento da agricultura.

A agricultura potencializava a exploração de recursos e marcava o início do avanço humano sobre a Natureza. O seu desenvolvimento, associado ao da pecuária, determinou a primeira grande divisão social do trabalho: algumas tribos tornaram-se criadoras e outras pastoras. A vida sedentária os ensinou a importância de armazenarem seus alimentos e de se prevenirem diante de eventuais períodos de escassez. Disseminou-se a produção e a troca de excedentes. Essa especialização originária do metabolismo estabelecido entre o homem e a Natureza, determinou o próprio modo de vida dos homens de então: uns se apegaram a terra tomando para si um padrão de vida mais sedentário, outros mantiveram certo grau de nomadismo ao viverem pastoreando seus rebanhos. Essa divisão do trabalho material e espiritual também demarcou o advento de uma precária propriedade privada, germe da sociedade de classes.

Como se pode observar, a interação metabólica que os homens estabelecem entre si e com o meio resulta de fatores histórico-culturais inerentes às relações sociais dominantes em cada época e lugar. Essas relações advêm do ato de produzir as condições materiais de vida necessárias para a sua sobrevivência biológica e para sua a reprodução social. Segundo Marx e Engels (1984), o desenvolvimento de um modo de vida decorre em correspondência às forças produtivas e às relações de produção prevalecentes em determinada sociedade:

Este modo de produção não deve ser considerado no seu mero aspecto reprodução da existência física dos indivíduos. Trata-se já, isso sim, de uma forma determinada da atividade destes indivíduos, de uma forma determinada de exprimirem a vida, um determinado modo de vida dos mesmos. Aquilo que eles são, coincide, portanto, com a sua produção, com o que produzem e também o como produzem. Aquilo que os indivíduos são, depende, portanto, das condições materiais da sua produção (Marx e Engels 1984, p. 15).

Da Natureza, os homens retiram os meios necessários à manutenção da vida da espécie. A partir dela, ampliam a capacidade de produzir órgãos exossomáticos e as possibilidades de transformarem o meio em que vivem. Essa permuta é dialética, no sentido de que estes transformam a Natureza ao mesmo tempo em que por esta são transformados. Não obstante, essa troca metabólica estabelece definitivamente suas dependências em relação ao ambiente. Segundo Marx, em Manuscritos Econômicos e Filosóficos, a Natureza corresponde ao "corpo inorgânico do homem":

A natureza é o corpo inorgânico do homem; quer isso dizer a natureza excluindo o próprio corpo humano. Dizer que o homem vive da natureza significa que a natureza é o corpo dele, com o qual deve manter em contínuo intercâmbio a fim de não morrer. A afirmação de a vida física e mental do homem e a natureza são interdependentes simplesmente significa ser a natureza interdependente consigo mesma, pois o homem é parte dela (Marx 1975, p.95).

A sobreposição dos homens à Natureza ocorreu com o intuito de dominá-la a qualquer custo e de ampliar a produtividade agrícola, para tal fizeram uso de agrotóxicos e de pesticidas de toda ordem, quebrando com a relação de equilíbrio biótico. Com a produção de mercadorias em série exigia-se e exige-se o consumo em larga escala de matéria prima e de matéria bruta e o crescente dispêndio de energia extraídos em profusão até o limite do esgotamento. Como resultado dessa alienação, a relação dos homens com o ambiente foi ressignificada e submetida a um estranhamento, a uma troca metabólica assimétrica, baseada em um assenhoramento objetivante e reificado da Natureza. Contrapondo-se ao pensamento dominante na sociedade capitalista prevalecente em sua época, Marx e Engels discorreram sobre a diferença entre uma relação metabólica essencial estabelecida 
entre os homens e a Natureza e uma troca alienada, fundada em um não-pertencimento ecológico, alertando para os danos socioambientais decorrentes do modo de produzir industrial:

A “essência" do peixe é o seu "ser", a água - para nos ficarmos por esta proposição. A “essência” do peixe de água doce é a água de um rio. Mas esta deixa de ser a "essência" do peixe, e já não é um meio adequado de existência, assim que o rio é posto ao serviço da indústria, assim que é poluído com tintas e outros produtos residuais, e navegado por barcos a vapor, ou assim que a sua água é conduzida para canais onde bastam os esgotos para privar o peixe do seu meio de existência (Marx e Engels 1984, p. 55).

O alerta de Marx sobre a importância do equilíbrio ecossistêmico não produziu eco. Para o pensamento capitalista era preferível dar vasão a ideias modernas de Francis Bacon e René Descartes. O primeiro, considerado pai da ciência moderna, sugeriu que a Terra e seus recursos naturais deveriam ser dominados, subjugados e torturados. É dele a máxima de que "saber é poder", refletido a necessidade do assujeitamento da Natureza. Com o segundo, a ciência ganhou o status de prova última do conhecimento e verdade inquestionável, o homem foi guindado a condição de "sujeito" e o meio ambiente reduzido a seu objeto externo, percebível pelo uso dos sentidos. Para conhecê-la, fazia-se necessário reduzi-la, decompondo-a a partes cada vez mais elementares, distintas entre si, até atingir verdades matemáticas. A consolidação desse modelo de pensamento correspondeu à supremacia da "dominação humana triunfalista sobre a natureza" (Harvey 2011, p. 152). Dissociados da Natureza, os homens se tornaram estranhos ao ambiente natural. Esse processo de alheamento se consolida com o advento da sociedade capitalista no século XVIII e vem se aprofundando com o alargamento da contradição em processo.

Movido por sua contradição central, o sistema do capital acelerou o processo de subsunção da Natureza a si. Novas forças produtivas tecnológicas e novos materiais foram desenvolvidos a partir do advento da nanociência, da biotecnologia e da engenharia de materiais. A nanociência compreende a nova fronteira da expansão capitalista, evidenciando o avançado estágio de subsunção do trabalho, da ciência, da tecnologia e da Natureza a si. O capital adentrou no processo de desenvolvimento de uma segunda natureza, aquela produzida artificialmente, "de aspecto físico e biológico inteiramente diverso, porque a simples manipulação externa da natureza se esgotou" (Kurz 2004, p. 235). Assim, esse avanço se prenuncia como mais um dos sintomas do eclipse da sociedade edificada sobre a égide do valor.

Como deve ter ficado claro, a lógica do sistema do capital contém um potencial de danos que se desenvolve na mesma velocidade do crescimento da produção, acompanhado o dilatamento da contradição central. A roda da acumulação sobrepõe-se ao atendimento de necessidades humanas reais e causa impactos irreversíveis ao ambiente. $\mathrm{O}$ avanço científico-tecnológico, por sua vez, vincula-se estreitamente a esta imanência e o lema "cada um por si e o mercado contra todos" exacerba o processo. Nessa perspectiva, a Natureza não é vista como algo a ser valorizado e apreciado, como um fim em si, mas, sobretudo, um meio para ser rentabilizado, para produzir lucro e mais acumulação de capital. Como não há limites para a sua ação expansiva, o capital vai continuar se expandindo, pondo em risco a própria vida planetária. Para fazer frente ao seu sociometabolismo totalizador, pressupõe-se a "reestruturação radical do modo predominante de intercâmbio e controle humano, é o pré-requisito necessário para um controle efetivo das forças da natureza” (Mészáros 2009, p.53). Eis o alcance do desafio que a humanidade tem de si defrontar para fazer frente à alienação proveniente do sistema mais totalizador já constituído pela humanidade em toda a sua história.

Perspectivas socioprodutivas e Natureza 
Sob o mantra da racionalidade da economia neoclássica dá-se a maximização utilitarista. Em sua ótica, bom corresponde ao que pode propiciar retorno imediato aos capitais no mercado. Com tal orientação unidirecional, a escala da produção sem limites avança sobre os meios de produção industriais eliminando participação dos trabalhadores imediatos (limite absoluto interno). Na mesma proporção, se precipita sobre a Natureza (limite absoluto externo) para adequá-la a suas necessidades de reprodução exacerbando a capacidade de suporte dos ecossistemas. Essa dupla ação depreciativa empreendida pelo sistema do capital é percebida por Foster $e t$ al., como partes de suas promessas não realizáveis: “Apesar de sua promessa de civilização e de modernização, o capitalismo, realmente, nunca superará a brutal barbárica relação com os seres humanos e a natureza; ao contrário, ele tem solapado ambos numa escala crescente" (2010b, p. 206 - Tradução livre).

Em síntese, de acordo com as argumentações até aqui apresentadas, crescimento econômico ilimitado acarreta alterações das condições naturais que vigoram em dado época e lugar. Tais transformações não são outra coisa que não o desencadeamento de processos irreversíveis, cujas consequências se desdobram de maneira diferenciada junto às espécies existentes. Está claro que "A reprodução do capital não pode integrar-se ao objeto da ecologia. Por isso, o estudo da transformação dos ecossistemas implica a articulação dos efeitos do modo de produção sobre os efeitos naturais biológicos proveneientes da estrutura funcional de cada ecossistema" (Leff 2002, p. 35). Como não é possível prever a intensidade, a direção e os efeitos sobre a diversidade dos ecossistemas, a melhor atitude deve ser a precaução.

O pensamento neoclássico em suas equações econométricas ocupa-se da maximização do lucro. É como se o desenvolvimento econômico constituísse um "valor neutro" e um fim em si mesmo. "Dessa forma, a racionalidade econômica baniu a natureza da esfera da produção, gerando processos de destruição ecológica e degradação ambiental” (Leff 2015, p. 15). Em sentido contrário à lógica posta pela valorização do valor, o pensamento ecossistêmico vê o interesse coletivo. Ele visa o equilíbrio entre homem e natureza, entre produção, consumo e capacidade de recomposição dos recursos e serviços da Terra. Pauta-se pelo compromisso das gerações presentes com as do amanhã e pelo respeito aos limites de resiliência socioambiental. Assim, embute a equação biótica entre o uso presente e a atenção para o futuro. Em Pequeno tratado do decrescimento sereno, Latouche critica veementemente o pensamento que move as sociedades ocidentais e fundamenta o crescimento econômico ilimitado,

[...] cujo motor não é outro senão a busca do lucro por parte dos detentores do capital, com consequências desastrosas para o meio ambiente e, portanto, para a humanidade. Não só a sociedade fica condenada a não ser mais que o instrumento ou o meio da mecânica produtiva, mas o próprio homem tende a se transformar num refugo de um sistema que visa a torná-lo inútil e a prescindir dele (2009, p. 4).

Particularmente, quando Latouche chama a atenção para a transformação do ser humano em um "refugo de um sistema", nos permite admitir a possibilidade da extinção desta espécie. No limite, caso ocorra o desaparecimento de todas as espécies vivas - animais e vegetais -, a mecânica seria declarada vencedora - quem faria a declaração? - e ficaria estabelecido o reino dos processos reversíveis. "Se o conhecimento científico não se emancipar da lógica de uma objetivação desumana da natureza, o complexo econômico-científico logrará transformar a Terra num deserto da física" (Kurz 2004, p. 238).

Diante da irreversibilidade inerente aos processos de extração de recursos e deposição de resíduos, Latouche propõe o decrescimento como possibilidade para postergar a existência da espécie humana. Trata-se de uma ideia que nos instiga a repensar o estilo de vida ocidental e a aprofundar o debate sobre "democracia ecológica 
local" (Latouche 2009, p. 59) como um contraponto à democracia representativa, para reafirmar a "autonomia econômica local" (Latouche 2009, p. 64) e estabelecer processos de democracia direta e de justiça socioambiental, extirpando o "racismo ambiental" (Herculano 2008). Ao mesmo tempo, acrescentemos, é preciso considerar os direitos da Terra, a fim de possibilitar o acesso de todas as espécies vivas aos bens comuns.

Podemos dizer que a ideia de decrescimento nos induz a pensar na necessidade de uma organização sociopolítica e ambiental, com a qual se possam criar condições para o desenvolvimento do "território como lugar de vida em comum [...] preservado e cuidado para o bem de todos" (Latouche 2009, p. 61). Provavelmente, estaríamos diante de uma escolha consensual inteligente. Mas isso contraria o primado da economia do crescimento econômico ilimitado. A constituição de uma nova economia ecológica exige que se reveja radicalmente o modo de produzir dominante, os recursos energéticos (humanos e naturais) e a intensidade como são despendidos e a relação entre presente e futuro da biodiversidade. Nos termos de Mészáros, o repensar as relações socioambientais exigem "uma reestruturação radical do modo predominante de intercâmbio e controle humano é o pré-requisito necessário para um controle efetivo das forças da natureza" (2009, p. 53).

De acordo com a teoria econômica mecanicista, o decrescimento exporia a sociedade a incertezas, desemprego, cortes de programas sociais - saúde, educação, seguridade. Ao contrário, seus divulgadores propagam o crescimento econômico como necessário para que ocorram avanços tecnológicos, ganhos de escala e posterior crescimento, a fim de que esses problemas sejam resolvidos e objetivos ecológicos sejam alcançados. Nada mais absurdo diante dos riscos ambientais que nos rodeiam e dos processos irreversíveis que esse mesmo crescimento desencadeia. Em seu senso comum douto o pensamento neoclássico não conjuga em sua escala teórica que “desenvolvimento linear e crescente rumo ao futuro não é universalizável” (Boff 2009, p. 13).

Decididamente, a teoria econômica convencional é ecologicamente analfabeta e seu método de análise reducionista. Em particular, a macroeconomia - clássica, keynesiana, neoclássica ou monetarista - desconsidera os limites ecológicos porque não tem nenhum critério, mesmo que irrealista, para estabelecer uma escala macroeconômica ótima. Não percebe que "a valorização dos recursos naturais está sujeita a temporalidades ecológicas de regeneração e produtividade que não correspondem aos ciclos econômicos” (Leff 2015, p. 65). Em raros momentos faz referência aos recursos naturais e em nenhum aos limites ecológicos. Ao contrário, prioriza a busca incessante do crescimento econômico como única via para alcançar o propalado bem-estar social. Em tom de ironia, Altvater estabelece uma crítica às teorias neoclássicas por estas desconhecerem os planos histórico-geográficos das relações que se estabelecem entre os homens e a Natureza:

O sistema categorial só pode ser salvo se o tempo e o espaço, isto é, se as dimensões da natureza forem retiradas da teoria e colocadas, por assim dizer, entre parênteses. A economia deve ser entendida como um acontecimento além do tempo histórico e do espaço geográfico (2010, p. 166).

A cegueira dos apologistas da economia capitalista de mercado os leva a pensar que é possível substituir os "bens comuns" pela produção humana. É uma perspectiva que ganhou folego desde que a indústria estabeleceu sua hegemonia econômica. É uma leitura mecanicista da vida, típica da teoria econômica. Por isso, a ética é, na maioria das vezes, polidamente ignorada em nome da macrométrica do lucro. A esclerose do sistema e o "autismo" de seus administradores e ideólogos contaminam a população de todo o mundo, impedindo-a de perceber que a fartura hoje disponível traz consigo uma fratura metabólica que se manifesta em eventos climáticos intensos e frequentes e em uma crescente montanha de lixo. $\mathrm{O}$ futuro previsível é a escassez de recursos naturais e a privação da grande maioria da população. Esse pensamento sobre a irracionalidade capitalista é corroborado 
por Loureiro (2012, p. 19): “A questão de fundo é que não parece ser possível transformar a relação humanonatureza sem transformar simultaneamente as relações sociais, porque as dinâmicas entre as esferas social e natural estão articuladas na mesma conjuntura societária".

Desse modo, a humanidade encontra-se aprisionada a um sistema por ela mesma criado e que põe em risco sua permanência na Terra. Trata-se de um organismo voraz que desestrutura os modos de vida dos territórios existentes, mesmo aqueles que ainda resistem a sua ação predatória. Ademais, cerceia o livre desenvolvimento das individualidades, incluindo-se a liberdade de pensar diferente, e impede a participação das pessoas nas decisões políticas cruciantes que afetam a vida das gerações atuais e futuras. Com isso, aprofunda a ruptura metabólica que assola o mundo, ao mesmo tempo em que afirma como revolucionária a perspectiva ecológica (Foster et al. 2010b). Faz-se necessária a construção de uma consciência socioambiental, fundamentada na economia ecológica, que busque construir uma nova relação dos homens entre si e destes com a Natureza a partir da disseminação de uma democracia direta e de uma organização local de base comunal e ecológica.

Assim, o princípio de gestão participativa dos recursos se integra a lutas emergentes por uma democracia a partir das bases. Esta democracia no processo produtivo vai além da democracia formal e representativa. Ela aponta para uma reapropriação dos recursos naturais e para a gestão coletiva dos bens e serviços ambientais das comunidades (Leff 2015, p.81).

Decrescimento também não deve ser confundido com “desenvolvimento sustentável”, o qual é alardeado de forma encantatória, mas cuja função não é outra senão legitimar o modo de produção e de vida da sociedade capitalista sem alterar seu rumo (Latouche 2009). Para caracterizar o que denomina "círculo virtuoso de decrescimento sereno", Latouche (2009, p. 42) propõe oito mudanças interdependentes, que se reforçam mutuamente, expressas pelos vocábulos: "reavaliar", "reconceituar", "reestruturar", "redistribuir", "relocalizar", “reduzir", "reutilizar" e "reciclar". Dentre outros aspectos, podemos dizer que os termos sugerem a necessidade de reorientar a pesquisa científico-técnica de modo que a nova estrutura econômico-científica não comprometa a capacidade de suporte dos ecossistemas e não reduzam os serviços ambientais por eles gerados. Também mostram que a insistência dos administradores do sistema de que o crescimento continuado é essencial para a estabilidade econômica, social e política, somente aumenta as desigualdades sociais e econômicas e os impactos ecológicos, comprometendo as condições de vida no longo prazo. $\mathrm{Na}$ impossibilidade de dar prosseguimento a essa trajetória, e para evitar o colapso, "a solução para a alienação dos seres humanos em relação à natureza, insistiu Marx, só seria descoberta no reino da prática, na história humana” (Foster 2010a, p. 115). De sua parte, Latouche nos convida a exercitarmos esse reino da prática numa escala de decrescimento econômico.

\section{REFERÊNCIAS BIBLIOGRÁFICAS}

Altvater E. 2010. O fim do capitalismo como conhecemos. Tradução de Peter Naumann. Rio de Janeiro: Civilização Brasileira.

Bauman Z. 2009. Vida líquida. Rio de Janeiro: Jorge Zahar.

Bauman Z. 2005a. Vida para consumo: a transformação das pessoas em mercadorias. Tradução Carlos Alberto Medeiros. Rio de Janeiro: Jorge Zahar. 
Bauman Z. 2005b. Vidas desperdiçadas. Rio de Janeiro: Jorge Zahar.

Boff L. 2009. Ética da vida: nova centralidade. Rio de Janeiro: Record.

Capra F, et al. 2006. Alfabetização ecológica: a educação das crianças para um mundo sustentável. São Paulo: Cultrix.

Debord G. 2003. A sociedade do espetáculo. eBookLibris, Projeto Periferia. Disponível em: < $\underline{\text { http://www. }}$ cisc.org.br/portal/biblioteca/socespetaculo.pdf>. Acesso em: 16 nov. 2013.

Engels F. 2009. A origem da família, da propriedade privada e do estado. Tradução Ruth M. São Paulo: Klauss Centauro,

Foster JB. 2010a. A ecologia de Marx: materialismo e natureza. Rio de Janeiro: Civilização Brasileira.

Foster JB, Clark B, York R. 2010b. The Ecological Rift - Capitalism's war on the Earth. Monthly Review Press, New York.

Harvey D. 2011. O Enigma do capital e as crises do capitalismo. São Paulo: Boitempo Editorial.

Herculano S. 2008. O clamor por justiça ambiental e contra o racismo ambiental. InterFaceHS - Revista de Gestão Integrada em Saúde do Trabalho e Meio Ambiente, 3(1), 1-20 p.

Kurz R. 2004. Com todo vapor ao colapso. Juiz de Fora, MG: Editora UFRJ - Pazulin.

Latouche S. 2009. Pequeno tratado do decrescimento sereno. São Paulo: WMF.

Leff E. 2015. Saber ambiental. $11^{\mathrm{a}}$ Ed. Petrópolis, RJ: Vozes.

Leff E. 2002. Epistemologia Ambiental. 5ª Ed. São Paulo: Cortez Editora.

Loureiro B. 2012. Trajetória e Fundamentos da Educação Ambiental. $4^{a}$ Ed. São Paulo: Cortez Editora.

Marques M. 2016. O capital em crise: educação e qualificação-desqualificante. Fortaleza: Expressão gráfica e Editora.

Marx K, Engels F. 1984. A ideologia alemã. São Paulo: Editora Morais.

Marx K. 1985. O Capital: crítica da economia política. Vol. 1. Tradução de Regis Barbosa e Flávio R. Kothe, $2^{\mathrm{a}}$ edição. São Paulo: Ed. Nova Cultural.

Marx K. 1972. Elementos Fundamentales para la Crítica de la Economía Política (Grundrisse) 1857 1858, vol. 1, Siglo Veintiuno, $10^{2}$ edición, México.

Marx K. 1972. Elementos Fundamentales para la Crítica de la Economía Política (Grundrisse) 1857 1858, vol. 2, Siglo Veintiuno, 10ª edición, México.

Meadows DH. 2008. Thinking in systems: a primer. Editado por Diana Wright, Sustainability Institute. Chelsea Green Publishing. White River Junction, Vermont. 
Mészáros I. 2009. A crise estrutural do capital. Tradução de Francisco Raul Cornejo [et al]. São Paulo: Boitempo Editorial.

Mészáros I. 2002. Para além do capital: rumo a uma teoria da transição. Tradução de Paulo César Castanheira e Sérgio Lessa. São Paulo: Boitempo Editorial e Editora da UNICAMP.

Oliveira AA. 2006. Para uma socioeconomia política da transição: possibilidades e limites da economia solidária. Tese de Doutorado Programa de Pós-Graduação em Sociologia da Universidade Federal do Ceará. Fortaleza-Ce.

Sennett R. 1998. O declínio do homem público: as tiranias da intimidade. Tradução de Lygia Araújo Watanabe, $5^{\text {a }}$ edição. São Paulo: Companhia das Letras.

Wallerstein I. 1979. The capitalist world-economy. Cambridge: Cambridge University Press. 